\title{
Role of CT in Documenting the Extent of Temporal Bone and Middle Ear Involvement among Patients with Chronic Otitis Media
}

\author{
V. Tamilarasan ${ }^{1}$, G. Yuvabalakumaran², Md. Ameen ${ }^{3}$, Vinay Jadhav $^{4}$ \\ ${ }^{1}$ Assisstant Professor, Department of Radiology, ${ }^{2}$ Assisstant Professor, Department of Radiology, ${ }^{3}$ Professor \& HOD, \\ Department of Radiology, ${ }^{4}$ Professor, Department of Radiology, Trichy SRM Medical College, Hospital and Research Centre, \\ India
}

Corresponding author: Dr. G. Yuvabalakumaran, Assisstant Professor, Department Of Radiology, Srm Medical College, Hospital and Research Centre, Irungalur, Trichy-621105, India

DOI: http://dx.doi.org/10.21276/ijcmsr.2019.4.4.1

How to cite this article: V. Tamilarasan, G. Yuvabalakumaran, Md. Ameen, Vinay Jadhav. Role of CT in documenting the extent of temporal bone and middle ear involvement among patients with chronic otitis media. International Journal of Contemporary Medicine Surgery and Radiology. 2019;4(4):D1-D5.

\section{A B S T R A C T}

Introduction: Chronic suppurative Otitis Media (CSOM) one of the common morbidities encountered in clinical practice. Radiological evaluation by CT can play a vital role in understanding the extent of disease and in turn planning appropriate treatment. Study aimed to analyse the radiological profile of temporal bone and middle ear involvement among patients with chronic otitis media. To compare the extent of temporal bone and middle ear involvement among patients with chronic otitis media, as documented by CT, with intraoperative findings.

Material and Methods: The present study was a prospective study involving 87 study participants. It was conducted for a duration of one year between April 2018 to March 2019. Data were analysed by mean $\pm S D$, frequency and percentage for numeric and categorical variables. Sensitivity and specificity of CT findings against intraoperative findings were presented for all key findings.

Results: A total of 87 subjects were included in the final analysis. In the study, Otorrhea (80\%) was the most common presentation. Central perforation was seen in 31 (35.63\%) and least was attic perforation was observed in 15 (17.24\%) participants. In our study, CT had shown sensitivity beyond $90 \%$ for the majority of the findings related to middle year involvement, ossicle involvement and Characteristics of the mastoid bone. Least sensitivity (75\%) was found for stapes involvement, followed by incus involvement (85.7\%). Specificity was $100 \%$ for most of the parameters, with least sensitivity (81.8\%) found for hypotympanum. CT could not identify Tegmen tympani erosion.

Conclusion: CT can be a very useful evaluation tool to document the involvement of middle ear and mastoid bones among patients with CSOM, considering its high sensitivity and specificity.

Keywords: Computed tomography, Chronic Otitis Media, Intraoperative Findings

\section{INTRODUCTION}

Otitis media (OM) also known as middle ear inflammation is a spectrum of diseases, which includes acute otitis media (AOM), otitis media with effusion (OME; 'glue ear') and chronic suppurative otitis media (CSOM). Although OM may resolve spontaneously without complications, it can have associations with loss of hearing and life-long sequelae. ${ }^{1}$

Problems in behaviour and development of speech, language and cognitive abilities comprise as risks for infants with severe and recurrent OM and persistent middle ear effusion. Parent stress remaining constant the cost estimates around ( $>5$ billion in the United States). ${ }^{2}$ OM-related hearing impairment has a prevalence of 30.82 per ten-thousand. Each year 21thousand people die due to complications of OM. ${ }^{3}$
Acute OM occurs commonly in children than inadults. ${ }^{4}$ AOM incidence rate is $10.85 \%$, i.e. 709 million cases each year while $51 \%$ of these are under-fives. ${ }^{3}$ Streptococcus pneumoniae, Moraxella catarrhalis and Haemophilus influenzae are considered as major bacterial pathogens in AOM..$^{5}$ A comparatively common complication of AOM is acute mastoiditis. ${ }^{6}$

The chronic suppurative OM incidence rate is $4.76 \%$, i.e. 31 million cases, with $22.6 \%$ of cases occurring annually in under-fives. ${ }^{3}$ Complications of CSOM can be classified as extracranial (EC) or intracranial (IC). ${ }^{7}$ Prevalence surveys showed that the global burden of illness from CSOM involves 65-330 million individuals with draining ears, $60 \%$ of whom (39-200 million) suffer from significant hearing impairment. CSOM accounts for 28000 deaths and a disease burden of over 2 million DALYs. ${ }^{8}$

Chronic otitis media can be due to chronic mucosal disease 
or cholesteatoma. The differentiation between the two is generally done by clinical examination. The computed tomography (CT) scan is the standard imaging technique for the temporal bone but stays in controversy for its exact role in the preoperative assessment of patients with chronic otitis media. ${ }^{9}$ The technique provides information regarding the extent of disease as well as possible anatomic variations and potential complications that may be avoided during surgery. The imaging modality illustrates the detailed nature and extent of the prior mastoid surgery. CT of the temporal bone is, therefore, a useful guide to the surgeon in managing patients after unsuccessful surgery. ${ }^{10}$

Hence this study was conducted to analyse the radiological profile of temporal bone and middle ear involvement among patients with chronic otitis media treated in a tertiary care teaching hospital as well as to compare the extent of temporal bone and middle ear involvement among patients with chronic otitis media, as documented by $\mathrm{CT}$, with intraoperative findings.

\section{MATERIAL AND METHODS}

Our study was a prospective observational study conducted from April 2018 to March 2019. It was undertaken in the Department of Otorhinolaryngology, SRM Medical College and Hospital, Trichy. We included people suffering from CSOM and treated with surgical intervention.

A total of 87 subjects were included in the final analysis. Informed consent was obtained from patients before recruiting them in the study. After obtaining the informed written consent, all the patients were subjected to thorough clinical evaluation. All the patients were subjected detailed radiological assessment by Siemens 64 slice computed tomography The images were screened by a senior radiologist and involvement of various structures including middle ear, ossicles and mastoid bone were documented. The need for surgery was assessed by consultant otorhinolaryngologist. All the patients were counselled regarding the nature of the disease and the surgery. The outcome was explained to the patient with possible complications and improvements. Study subjects underwent mastoidectomy by a postural approach, and intraoperative findings were noted. Every participant was followed up to the end of the study. All the radiological findings were tabulated and correlated with intra-operative findings.

Descriptive analysis was done by mean and standard deviation for numeric variables, frequency and proportion for categorical variables. The utility of the CT in diagnosing the extent of involvement of various structures was assessed by comparing it with intra operative findings. Sensitivity, specificity, false positive rate and false negative rates were calculated and tabulated for different anatomical structures. IBM SPSS statistical software version 21 was used for data analysis.

\section{RESULTS}

A total of 87 subjects were included in the final analysis. In the study, the majority (43.68\%) of the participants were aged between 16 to 40 years. $26.44 \%$ were aged 41 to 60 years. Among the study population, 39 (44.8\%) participants

\begin{tabular}{|l|c|c|}
\hline Parameter & Frequency & Percentage \\
\hline Age group & 2 & 2.30 \\
\hline $0-5$ & 19 & 21.84 \\
\hline $6-15$ & 38 & 43.68 \\
\hline $16-40$ & 23 & 26.44 \\
\hline $41-60$ & 5 & 5.75 \\
\hline Above 60 & 39 & 44.83 \\
\hline Gender & 48 & 55.17 \\
\hline Male & \multicolumn{3}{|c|}{} \\
\hline Female & Table-1: Descriptive analysis of age and gender in the study \\
population (N=87) \\
\hline
\end{tabular}

\begin{tabular}{|l|c|c|}
\hline Parameter & Frequency & Percentage \\
\hline Symptoms & 80 & 91.95 \\
\hline Otorrhea & 52 & 59.77 \\
\hline Hearing loss & 26 & 29.89 \\
\hline Otalgia & 12 & 13.79 \\
\hline Vertigo & 10 & 11.49 \\
\hline Nausea \& vomiting & 9 & 10.34 \\
\hline Headache & 8 & 9.20 \\
\hline Tinnitus & 8 & 9.20 \\
\hline Fever with chills and rigours & 7 & 8.05 \\
\hline Swelling behind ear & 5 & 5.75 \\
\hline Facial weakness & 16 & 18.39 \\
\hline Signs & 10 & 11.49 \\
\hline Post-auricular scar & 5 & 5.75 \\
\hline Mastoid tenderness & 5 & 5.75 \\
\hline Post auricular swelling & 3 & 3.45 \\
\hline Facial palsy & 1 & 1.15 \\
\hline Fistula test & \multicolumn{2}{|l|}{} \\
\hline Nystagmus & \multicolumn{2}{|l|}{} \\
\hline Table-2: Descriptive analysis of symptoms and signs in the \\
\hline \multicolumn{2}{|c|}{ study population (N=87) } \\
\hline
\end{tabular}

\begin{tabular}{|l|c|c|}
\hline Ear affected & Frequency & Percentage \\
\hline Right & 35 & 40.23 \\
\hline Left & 33 & 37.93 \\
\hline Bilateral & 17 & 19.54 \\
\hline Tympanic membrane & 31 & 35.63 \\
\hline Central perforation & 23 & 26.44 \\
\hline $\begin{array}{l}\text { Polyp and sagging metal wall } \\
\text { obstructing visualisation }\end{array}$ & 17 & 19.54 \\
\hline Marginal perforation & 15 & 17.24 \\
\hline Attic perforation & membrane findings \\
\hline Table-3: Descriptive of Ear affected and otoscopic tympanic \\
\hline
\end{tabular}

were male and remaining 48(55.1\%) participants were female. (Table 1)

In the study, the majority(80\%) of the participants reported symptoms were otorrhea, followed by hearing loss, otalgia, and vertigo was 59.77\%, 29.89\%, 13.79\% respectively. (Table 2)

Among the study population, 35 (40.23\%) participants had right side ear affect, 33 (37.93\%) participants had left side ear affect, 17 (19.54\%) participants had both side ears affect. 


\begin{tabular}{|c|c|c|c|c|}
\hline Parameter & CT & 10 & Sensitivity & Specificity \\
\hline \multicolumn{5}{|c|}{ The extent of middle ear involvement } \\
\hline Protympanum & 9 & 11 & 100 & 90 \\
\hline Mesotympanum & 21 & 17 & 90 & 87.5 \\
\hline Posterior tympanum & 19 & 18 & 100 & 87.1 \\
\hline Epitympanum & 8 & 43 & 96.5 & 100 \\
\hline Hypotympanum & 18 & 9 & 100 & 81.8 \\
\hline Peri-labyrinthine cells & 2 & 8 & 100 & 93.4 \\
\hline Aditus & 1 & 38 & 92.3 & 91.6 \\
\hline Antrum & 20 & 36 & 92.8 & 90.9 \\
\hline Mastoid air cells & 3 & 40 & 88.8 & 100 \\
\hline \multicolumn{5}{|l|}{ OSSICLE Involvement } \\
\hline Scutum & 30 & 31 & 98 & 100 \\
\hline Malleus & 19 & 20 & 98 & 100 \\
\hline Incus & 39 & 42 & 85.7 & 100 \\
\hline Stapes & 27 & 34 & 75 & 100 \\
\hline \multicolumn{5}{|c|}{ Characteristics of Mastoid bone } \\
\hline Well pneumatized mastoid & 35 & 35 & 100 & 100 \\
\hline Sclerotic mastoid & 38 & 39 & 98 & 100 \\
\hline Diploic mastoid & 8 & 9 & 98 & 100 \\
\hline
\end{tabular}

\begin{tabular}{|l|c|c|c|c|}
\hline Complication & CT & IO & Sensitivity & Specificity \\
\hline Facial canal dehiscence & 5 & 14 & 75 & 88 \\
\hline Tegmen tympani erosion & 0 & 3 & 0 & 100 \\
\hline Cochlea erosion & 3 & 2 & 97 & 75 \\
\hline Erosion mastoid cortex & 7 & 7 & 100 & 100 \\
\hline Sinus plate erosion & 9 & 12 & 87.5 & 96 \\
\hline Tegmen mastoideum erosion & 3 & 7 & 85 & 93 \\
\hline Posterior fossa dural plate & 1 & 8 & 100 & 88 \\
\hline LSCC erosion & 4 & 9 & 90 & 100 \\
\hline Mastoiditis and mastoid abscess & 9 & 12 & 94 & 95 \\
\hline Intracranial & 12 & 13 & 96 & 100 \\
\hline \multicolumn{2}{|r|}{ Table-5: Comparison of complications as documented by CT and Intraoperative findings. } \\
\hline
\end{tabular}

Central perforation was seen in $31(35.63 \%)$ and least was attic perforation was observed in $15(17.24 \%)$ participants. (Table 3)

In our study, CT had shown sensitivity beyond $90 \%$ for the majority of the findings related to middle year involvement, ossicle involvement and Characteristics of the mastoid bone. Least sensitivity (75\%) was found for stapes involvement, followed by incus involvement (85.7\%). Specificity was 100\% for most of the parameters, with least sensitivity (81.8\%) found for hypotympanum. (Table 4)

CT had good sensitivity in identifying most of the complications. But it could not identify Tegmen tympani erosion. The other features where CT had comparatively lesser sensitivity was Tegmen mastoideum erosion (85\%) and Sinus plate erosion (87.5\%). The specificity of CT was high for the majority of complications. Least specificity was observed for Cochlear erosion 975\%) and Posterior fossa dural plate (88\%). (Table 5)

\section{DISCUSSION}

Chronic otitis media (COM) continues to have a high prevalence in developing countries and frequently becomesa leading cause of deafness and morbid complication. ${ }^{11}$ Our study included 87 participants. The age group which had majority was between 16 to 40 years, and there was female dominant as compared to males. In a similar study age group with majority population involved were 21-30 years and female population dominance. ${ }^{12}$ In the current study, otorrhea was seen in majority participants with Postauricular scar. Right side ear was the most affected ear in the study population. An article described that CT had a high negative predictive value in cases with a free cavity after mastoidectomy. ${ }^{13}$

A series of 56 patients with COM undergoing preoperative CT scanning followed by a surgical exploration of the middle ear and mastoid showed weak specificity of preoperative CT scan in detecting facial canal dehiscence, dural plate erosion and sigmoid sinus. ${ }^{14}$ These results were in accordance with our study. Another research showed High resolution computed tomography(HRCT temporal bone offered sensitivity (Se) and specificity (Sp) of $100 \%$ for visualisation of sigmoid and tegmen plate erosion. The performance of HRCT in detecting malleus ( $\mathrm{Se}=100 \%, \mathrm{Sp}=95.23 \%$ ), incus $(\mathrm{Se}=100 \%, \mathrm{Sp}=80.48 \%)$ and stapes $(\mathrm{Se}=96.55 \%, \mathrm{Sp}=71.42 \%)$ 
erosion was excellent. Precise information about facial canal erosion ( $\mathrm{Se}=100 \%, \mathrm{Sp}=75 \%$ ), scutum erosion ( $\mathrm{Se}=100 \%$, $\mathrm{Sp}=96.87 \%$ ) and extension of disease to facial recess and sinus tympani ( $\mathrm{Se}=83.33 \%, \mathrm{Sp}=100 \%$ ) was obtained. The study showed the specificity of $100 \%$ for lateral semi-circular canal erosion $(\mathrm{Sp}=100 \%)$ but with low sensitivity $(\mathrm{Se}=53.84 \%) .{ }^{15}$ Similar findings were recorded in our study.

One research concluded that HRCT could be recommended not only in cases suspected with potential complications but also in all cases of COM to know the extent of disease, varied pneumatization, and the presence of anatomical variations, which would make the clinician aware and guide in surgical approach and treatment plan. ${ }^{16}$

A prospective study of 104 the sensitivity and specificity of HRCT for detecting malleus, incus and stapes erosion was 71.5 and $88.5 \%, 86.3$ and $95 \%$ and 53.1 and $64.7 \%$ respectively. The sensitivity and specificity for detecting the erosion of lateral semi-circular canal (LSCC) were 77.78 and $98.2 \%$; these findings also were similar to our study. ${ }^{17}$ Another study reports suggested that routine preoperative CT scanning of patients before uncomplicated virgin mastoid surgery is of questionable value. ${ }^{18}$

A study of Evaluation of 36 patients concluded that the CT scan can accurately predict the extent of disease and is helpful for detection of lateral canal fistula, erosions of the dural plate, and ossicular erosions yet unable to distinguish between cholesteatoma and mucosal disease, facial nerve dehiscence, incus, and stapes erosion. ${ }^{19}$ One of the articles gave conclusion stating HRCT temporal bone is a reliable investigation in preoperative evaluation of chronic otitis media and its complications, but unreliable for tegmen tympani and posterior fossa dural plate erosion. ${ }^{20}$ This was showing similarities with our results.

An investigation reported that preoperative CT temporal bone scan of patients with CSOM serves as an important guide in surgical approach for otolaryngologists, although there are limitations in the evaluation of the CT results in. ${ }^{21}$

A study conducted concluded that HRCT of the temporal bone was useful in finding the location and extent of disease in patients with chronic suppurative otitis media. ${ }^{22}$ Another research concluded that preoperative CT of Middle ear lesions being useful for surgery planning but some lesion may not be completely diagnosed by CT scan, and intraoperative assessment of surgical field is crucial. ${ }^{23}$

\section{CONCLUSION}

Majority of the operated patients were adults aged between 16 to 40 years. Otorrhea was the most common presentation, followed by hearing loss, otalgia, and vertigo. In our study, CT had shown sensitivity beyond 90\% for the majority of the findings related to middle year involvement, ossicle involvement and Characteristics of the mastoid bone. Least sensitivity was found for stapes involvement, followed by incus involvement. Specificity was $100 \%$ for most of the parameters, with least sensitivity found for hypotympanum. CT had good sensitivity in identifying most of the complications. But it could not identify Tegmen tympani erosion.

\section{REFERENCES}

1. Schilder AG, Chonmaitree T, Cripps AW, Rosenfeld RM, Casselbrant ML, Haggard MP, et al. Otitis media. Nat Rev Dis Primers. 2016;2(1):16063.

2. Klein JO. The burden of otitis media. Vaccine. 2000;19 Suppl 1:S2-8.

3. Monasta L, Ronfani L, Marchetti F, Montico M, Vecchi Brumatti L, Bavcar A, et al. Burden of disease caused by otitis media: systematic review and global estimates. PLoS One. 2012;7(4):e36226.

4. Limb CJ, Lustig LR, Klein JO. Acute otitis media in adults. UpToDate Welthem, MA: UpToDate. 2018.

5. Palmu AA, Herva E, Savolainen H, Karma P, Mäkelä PH, Kilpi TM. Association of clinical signs and symptoms with bacterial findings in acute otitis media. Clin Infect Dis. 2004;38(2):234-42.

6. Aljohani Z, Alghonaim A, Alhaddad R, ALShaif W, AlThomali R, Asiry A, et al. Otitis media causes and management. Int J Community Med Public Health. 2018;5(9):3703-8.

7. Yorgancilar E, Yildirim M, Gun R, Bakir S, Tekin R, Gocmez C, et al. Complications of chronic suppurative otitis media: a retrospective review. Eur Arch Otorhinolaryngol. 2013;270(1):69-76.

8. World Health Organization. Chronic suppurative otitis media: burden of illness and management options. Geneve: World Health Organization. 2004. Available From [https://apps.who.int/iris/handle/10665/42941].

9. Alzoubi FQ, Odat HA, Al-Balas HA, Saeed SR. The role of preoperative CT scan in patients with chronic otitis media. Eur Arch Otorhinolaryngol. 2009;266(6):807-9.

10. Campbell JP, Pillsbury HCr. The use of computerized tomographic imaging in revision mastoid surgery for chronic otitis media. Am J Otol. 1990;11(6):387-94.

11. Irwan AG, Widyasari F, Suyanti, Gunawan A. Pre and intraoperative findings of chronic otitis media. J Phys: Conf Ser. 2019;1246(1):012019.

12. Rai T. Radiological study of the temporal bone in chronic otitis media: Prospective study of 50 cases. Indian J Otol. 2014;20(2):48-55.

13. Kösling S, Bootz F. CT and MR imaging after middle ear surgery. Eur j radiol. 2001;40(2):113-8.

14. Yildirim-Baylan M, Ozmen CA, Gun R, Yorgancilar E, Akkus Z, Topcu I. An evaluation of preoperative computed tomography on patients with chronic otitis media. Indian J Otolaryngol Head Neck Surg. 2012;64(1):67-70.

15. Karki S, Pokharel M, Suwal S, Poudel R. Correlation between preoperative high resolution computed tomography (CT) findings with surgical findings in chronic otitis media (COM) squamosal type. Kathmandu Univ Med J (KUMJ). 2017;15(57):84-7.

16. Bhattacharjee L, Paul S. A comparative study between high resolution computed tomography findings and operative findings of squamous type of chronic otitis media. Indian J Appl Res. 2019;9(2):42-3.

17. Khan MI, Patel S, Dasgupta K. Is HRCT Temporal Bone Necessary in All Cases of Active Squamous Chronic Otitis Media? Indian J Otolaryngol Head Neck Surg. 2018:1-5.

18. Walshe P, McConn Walsh R, Brennan P, Walsh M. The 
role of computerized tomography in the preoperative assessment of chronic suppurative otitis media. Clin Otolaryngol Allied Sci. 2002;27(2):95-7.

19. Rogha M, Hashemi SM, Mokhtarinejad F, Eshaghian A, Dadgostar A. Comparison of Preoperative Temporal Bone CT with Intraoperative Findings in Patients with Cholesteatoma. Iran J Otorhinolaryngol.2014;26(74):712.

20. Nanjaraj CP, Nagarajegowda PH, Kannan VP, Nagarajaiah PKC. Chronic otitis media: high resolution computed tomographic evaluation of the temporal bone with surgical correlation. J Evid Based Med Healthc. 2016;3(40):1955-62.

21. Prakash MD, Tarannum A. Role of high resolution computed tomography of temporal bone in preoperative evaluation of chronic suppurative otitis media. Int J Otorhinolaryngol Head Neck Surg. 2018;4(5):1287-92.

22. Happani H, Kalola J, Rathod H, Trivedi A. Role of HRCT Temporal Bone In Patients with Chronic Supparative Otitis Media. Int J Contemporary Med Surg Radiol. 2018;3(3):C70-2.

23. Moghaddam YJ, Chalabianloo F. Comparison of Temporal Bone Tomography Findings of Chronic Otitis Media with Intraoperative Findings. Advanc Biosci Clin Med. 2019;7(2):17-9.

Source of Support: Nil; Conflict of Interest: None

Submitted: 23-07-2019; Accepted: 15-08-2019; Published online: 28-09-2019 